\title{
Gastric ulcer healing in the rat: kinetics and localisation of de novo procollagen synthesis
}

\author{
M Shahin, A Gillessen, T Pohle, C Weber, D Schuppan, H Herbst, W Domschke
}

\begin{abstract}
Background and aims-To gain further insight into the role of the extracellular matrix during healing of peptic ulcers, sequential changes of procollagen expression were studied over 30 days of ulcer healing.

Materials and methods-Procollagens $\alpha 1($ I), $\alpha 1($ III), and $\alpha 1($ IV) RNA and their polypeptides were assessed in acetic acid induced rat gastric ulcers by in situ hybridisation and immunohistochemistry.

Results-Three days after ulcer induction, intense hybridisation signals were obtained with all probes, with procollagen a1(I) showing the highest transcript levels. Procollagen gene expression remained elevated up to day 15 , but was reduced to initial low levels on day 30. Immunohistochemical staining documented increased deposition of the three procollagen types parallel to their respective transcript levels, again with type I showing the earliest and the most prominent deposits. The highest procollagen transcript levels were found in the intact submucosa surrounding the ulcer margins, followed by the muscularis propria and the serosa, with the lamina propria exhibiting the lowest transcript levels.

Conclusion-The procollagens studied are regulated differentially at the transcriptional and post-transcriptional levels. The early onset and long duration of procollagen expression as well as the involvement of all layers of the gastric wall points to their central structural and functional role in gastric ulcer healing. (Gut 1997; 41: 187-194)
\end{abstract}

Keywords: gastric ulcer; in situ hybridisation; procollagen RNA

Gastroenterology, Free

University of Berlin,

Germany

D Schuppan

Institute of Pathology,

University of

Hamburg, Germany

H Herbst

Correspondence to: Dr Manal Shahin,

Department of Medicine B,

University of Münster,

Albert-Schweitzer-Strasse 33, D-48129, Münster,

Germany.

Accepted for publication 28 January 1997

Ulcer healing requires interactions between different tissues and cell types to achieve restoration of the normal mucosal architecture. ${ }^{1}$ This active process is characterised by an initial replacement of the mucosal defect with proliferating and migrating epithelial cells that are supported by a meshwork of connective tissue components. Recent studies have indicated a pivotal role for the extracellular matrix (ECM) in wound repair, ${ }^{2}$ not only by providing the support for the regenerating cells, ${ }^{3}$ but also by creating the environment necessary for cellular interactions. ${ }^{4}$ Fibrillar collagens, in particular, are important for the generation of wound strength. Their role during the peptic ulcer healing process has however been analysed by few investigators. In a previous study we reported the distribution of the interstitial collagens, types I and III, in both the mucosa and submucosa of human normal gastric tissue and their increased deposition at the edges of the gastric ulcer. ${ }^{5}$ By immunohistochemistry, Lu et al studied the sequential changes in the distribution patterns of type III and IV collagens during the healing process of experimentally induced gastric ulcer, with deposition of type IV collagen being confined to the basement membrane of the regenerating mucosal glands and microvasculature and showing an increased immunoreactivity between the tenth and the twenty first day. ${ }^{6}$ However, these data only yielded a qualitative estimate. Recently, we were able to demonstrate de novo synthesis of collagen type I in healing human gastric ulcer by localising cells expressing procollagen type I RNA in the lamina propria of the ulcer edge and the submucosa. ${ }^{78}$

In this study we report on the time course in RNA transcript levels of procollagen $\alpha 1$ (I), $\alpha 1$ (III), and $\alpha 1$ (IV) genes over a period of 30 days of ulcer healing. Simultaneously, the amount of the respective collagenous proteins deposited at the ulcer region at various points of time was assessed semiquantitatively. Particular attention was focused on the localisation of the collagen expressing cells, their pattern of distribution in various structural layers of the gastric wall, and their route of migration to the healing zone. Finally, the sites of transcriptional activity and the location of active collagen deposition were correlated. We used the well established acetic acid induced ulcer model in rat as described by Okabe et al and Tarnawski et $a l,{ }^{10}$ who reported on the sequence of events after serosal application of acetic acid. The mechanism of ulcer formation is probably related to the development of thrombi in the submucosal vessels and collecting venules resulting in ischaemic mucosal necrosis and ulcer formation. ${ }^{10}$

\section{Methods}

ULCER INDUCTION AND TISSUE SAMPLING

Forty eight male Wistar rats weighing 230$280 \mathrm{~g}$ at the time of operation, deprived of food for about 16 hours (water ad libitum), were anaesthetised with a mixture of diazepam and ketamine $(3 \mathrm{mg} / \mathrm{kg}$ and $87 \mathrm{mg} / \mathrm{kg}$, respectively) intraperitoneally. A median laparotomy was performed and the stomach exposed. In 24 rats $70 \mu \mathrm{l}$ of $100 \%$ acetic acid was applied within a plastic mould ( $5 \mathrm{~mm}$ diameter) tightly placed 
on the anterior serosal surface of the antrum along the lesser curvature for 30 seconds. It was then removed, the exposed area rinsed with isotonic saline to minimise adhesion, and the abdomen closed. In the control group, consisting of 24 rats, isotonic saline was used instead of acetic acid.

To analyse the evolution and healing of the induced gastric ulcers, groups of eight rats (four treated animals and four controls) were sacrificed at three, five, seven, 12, 15, and 30 days after the initial manipulation and the stomach opened along the greater curvature. After gentle rinsing with isotonic saline the ulcer was stamped out through the whole thickness of the gastric wall and immediately snap frozen in liquid nitrogen, then kept deep frozen at $-80^{\circ} \mathrm{C}$ until used. Tissue samples were also obtained from the contralateral side of treated as well as from the antral regions of control animals. The study protocol was approved by the Animal Study Committee of the University of Münster and Münster county.

\section{DETECTION PROCEDURES}

In situ hybridisation

For the preparation of RNA probes, the cDNA fragments of rat $\alpha 1$ (I) and of mouse $\alpha 1$ (III) procollagen, harboured in the plasmids pa1R1 and pMCS, respectively, were subcloned into the plasmid pGEM1 (Promega Biotec, Heidelberg, Germany) at the appropriate restriction sites. ${ }^{112}$ PCIV, containing a mouse $\alpha 1$ (IV) cDNA fragment represents a pGEM1 vector. ${ }^{13}$ After linearisation of the plasmids with either EcoRI or HindIII restriction endonuclease, SP6 or T7 RNA polymerase (Gibco BRL, Karlsruhe, Germany), respectively, were used to obtain run-off transcripts of either the antisense (complementary to mRNA) or sense (anticomplementary, negative control) strands. ${ }^{14}$

In situ hybridisation (ISH) utilising ${ }^{35} \mathrm{~S}$ labelled single stranded RNA probes, complementary and anticomplementary, was performed as previously described ${ }^{15}{ }^{16}$ using frozen tissue sections $5 \mu \mathrm{m}$ thick collected onto amino-propyl-triethoxysilane (APES, Sigma, St Louis, MO, USA) coated slides and treated as described earlier. Autoradiographic exposure was terminated after one week for $\alpha 1$ (I) procollagen and after three weeks for $\alpha 1$ (III) and $\alpha 1(\mathrm{IV})$ procollagens. ISH experiments with sense probes showed only weak homogeneously distributed background signal. For ISH with antisense probes, signal intensity on the labelled cells was semiquantitatively evaluated as follows: strong when the accumulation of silver grains completely concealed the nuclei; weak when only a few silver grains were noted over the labelled cells; and moderate for the remainder of the labelled cells.

\section{Immunohistochemistry}

Parallel to in situ hybridisation analysis, immunohistochemical detection of collagen types I and IV, and procollagen type III in all gastric ulcer specimens was performed on frozen $5 \mu \mathrm{m}$ sections using the alkaline phosphatase anti- alkaline phosphatase (APAAP) technique. ${ }^{17}$ Rabbit antibodies to monkey skin collagen type I and procollagen type III as well as to the carboxyterminal domain of human placental collagen type IV (NC1) were characterised and used as described elsewhere. ${ }^{1819}$ The intensity of staining was graded in four categories: absent, weak, moderate, and strong staining. Negative controls were performed by omitting the primary antibody as well as by utilising a non-immune immunoglobulin $\mathrm{G}$.

Finally, the overall amount of procollagen deposited was measured semiquantitatively as the percentage surface area of specifically stained tissue (APAAP labelled) in an area of $200 \times 200 \mu \mathrm{m}$ using a computerised photo analysis system (Microscale IIc software, Digithrust Ltd, Nürnberg, Germany) as previously described. ${ }^{20}$ For calibration exclusively haematoxylin and APAAP stained sections were used as negative and positive controls, respectively. Measurements were performed in three representative regions of both mucosa and submucosa near the ulcer margin of each section and compared with normal tissue.

\section{Results}

MORPHOLOGICAL FINDINGS

On day 3 a fully developed ulcer (fig 1A) was clearly evident in all specimens with an average diameter of $5 \mathrm{~mm}$ and an average depth of $2 \mathrm{~mm}$. All ulcers penetrated the muscularis mucosae, and three perforated the entire thickness of the gastric wall with their base adherent to the liver. A macroscopic reduction in the ulcer size (diameter 3-4 mm) and depth of the lesion with the development of a round white scarring area was first observed on the twelfth day. Later exact measurements were not possible as the ulcer edges were no longer properly defined. Microscopically, up to day 30 the regenerated glands remained cystically dilated and the muscularis mucosae appeared disrupted (fig 1B). In comparison, the contralateral specimens displayed only slight oedema within the submucosa, while in control specimens neither macroscopic nor microscopic changes were observed.

\section{IN SITU HYBRIDISATION}

Controls and tissue contralateral to the ulcer

In all sham operated rats only low steady state levels of $\alpha 1$ (I), $\alpha 1$ (III), and $\alpha 1$ (IV) procollagen gene transcripts were seen, with signals essentially confined to the submucosa of specimens with normal histology (fig 2A). When compared with controls, the expression of mRNA was increased, both with respect to the number of labelled cells and to signal intensity, in the oedematous submucosal connective tissue of the contralateral ulcer region, where autoradiographic signals were found on spindle shaped cells (fig 2B).

\section{Experimentally induced gastric ulcers}

As summarised in table 1 , an extensive hybridisation signal for $\alpha 1$ (I) procollagen could be identified as early as three days after ulcer induction in all specimens, particularly in the widened intact submucosa near the overhang- 

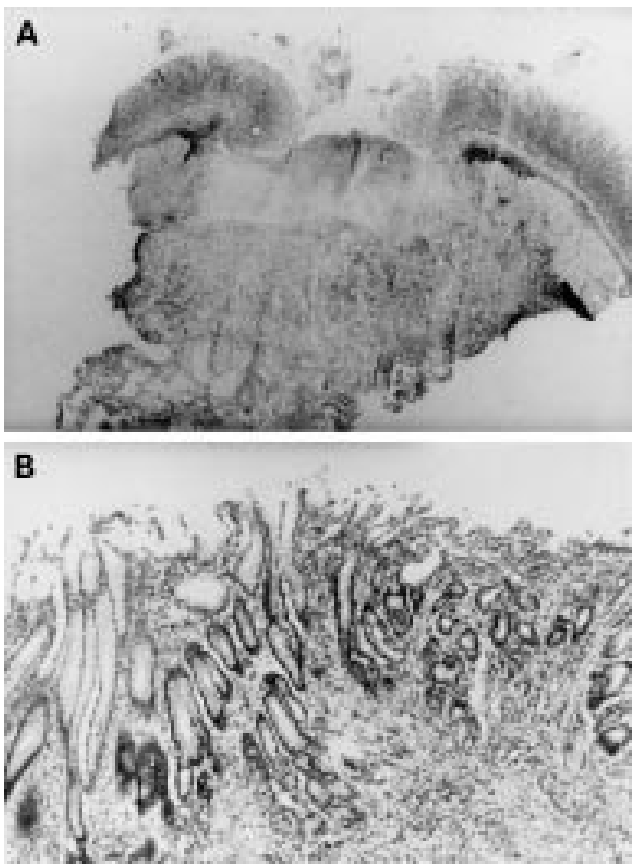

Figure 1: (A) Fully developed rat antral ulcer with overhanging edges three days after induction with acetic acid. The ulcer penetrates the muscularis mucosae as well as the muscularis propria. The ulcer floor is occupied by necrotic debris and a round cell infiltrate. (B) Complete mucosal re-epithelialisation on day 30 with marked cystic dilatation of the regenerated glands and the muscularis mucosae still disrupted. (A) Original magnification $\times 20$; (B) $\times 100$.

ing ulcer margin (figs $3 \mathrm{~A}$ and $3 \mathrm{~B}$ ). At the ulcer base slightly weaker signals were observed in the granulation tissue below the zone of necrosis (fig 3C). In contrast, control hybridisation with sense probes showed only a small number of scattered grains equivalent to low intensity signals considered as background in sections with specific binding (fig 3D). The high expression of procollagen $\alpha 1$ (I) RNA in the submucosa persisted up to day 15 . It was, however, not only confined to the submucosa, as prominent RNA expression could be also localised in the connective tissue cells between the circular and the longitudinal muscle layers of the muscularis propria, in cellular sheets along the muscle fibres (fig 4A), and in the serosa. In addition, hybridisation signals were detected underneath the epithelium, within the interglandular stroma of the upper and lower lamina propria (fig 4B). The muscularis mucosae did not contain any positive cells. On day 30 a notable reduction in the procollagen gene transcript level was evident.

The temporal and anatomical patterns of $\alpha 1$ (III) and $\alpha 1$ (IV) procollagen transcripts were similar to those of $\alpha 1$ (I) procollagen although the hybridisation signals were less intense (figs 5A and 5B). $\alpha 1$ (IV) procollagen gene transcripts were mainly found in the intermuscular connective tissue and in serosal layers rich in endothelial cells likely to be required for neovascularisation (fig 5C).

In the lamina propria, the signal intensity was decreased suggesting that RNA expression was down regulated around the time at which scarring became macroscopically evident. However, no relation was observed between the ulcer size and procollagen RNA expression in the submucosa as the major site of procollagen synthesis, as the hybridisation signal intensity did not increase or decrease with changes in ulcer size.

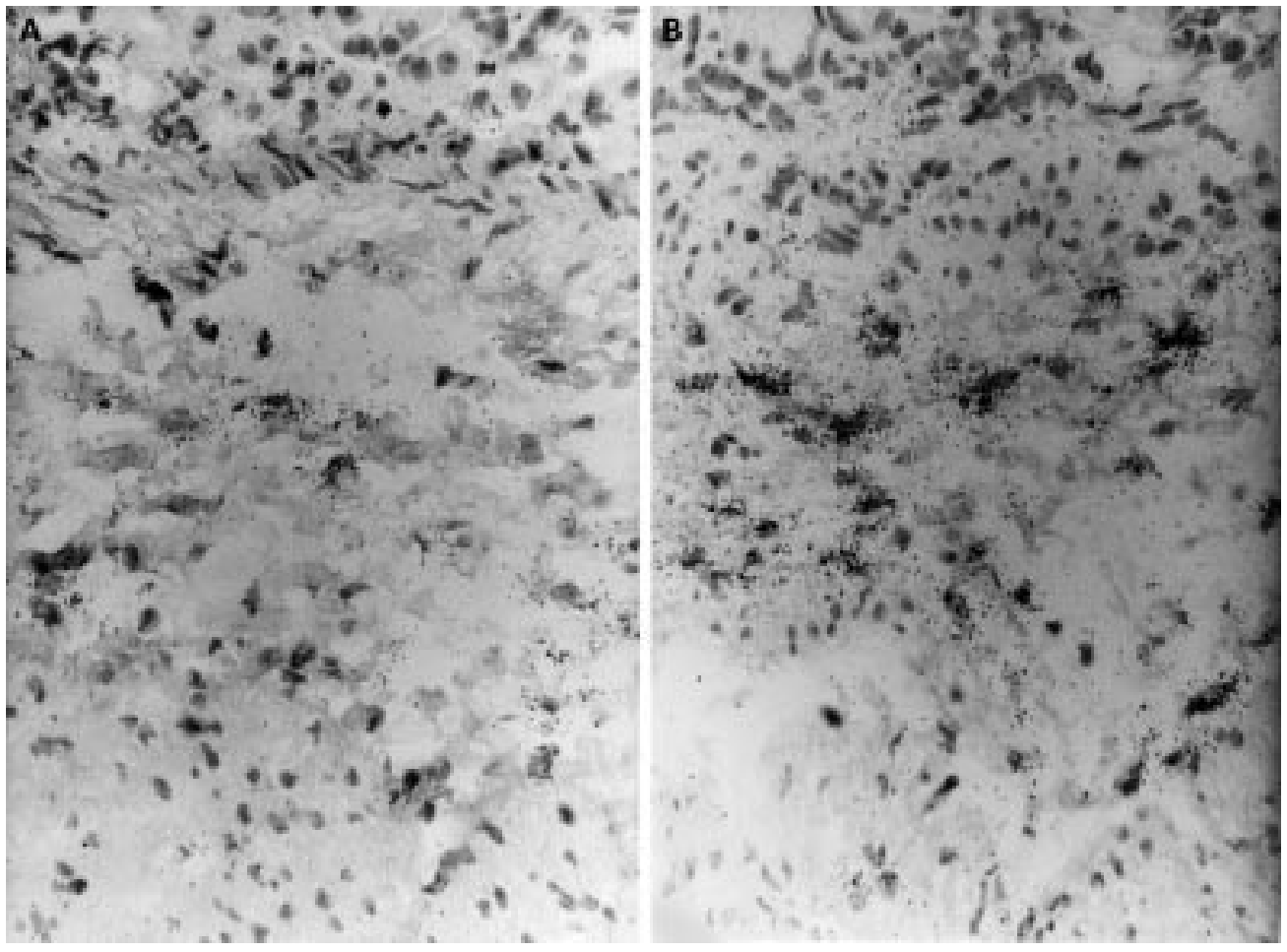

Figure 2: In situ hybridisation with the ${ }^{35}$ S labelled a1(I) procollagen antisense RNA probe. The gastric mucosa of a sham operated rat $(A)$ shows only minimal signal; in the gastric tissue contralateral to the ulcer $(B)$ the autoradiographic signals are obviously increased. Original magnification $\times 240$. 
TABLE 1 Summary of ISH results

\begin{tabular}{|c|c|c|c|c|c|c|c|c|c|}
\hline \multirow[b]{2}{*}{ Probe } & \multirow{2}{*}{$\begin{array}{l}\text { Days after } \\
\text { ulcer induction }\end{array}$} & \multicolumn{2}{|c|}{ Lamina propria } & \multicolumn{2}{|l|}{ Submucosa } & \multicolumn{2}{|c|}{ Muscularis propria } & \multicolumn{2}{|l|}{ Serosa } \\
\hline & & Contralateral & Ulcer & Contralateral & Ulcer & Contralateral & Ulcer & Contralateral & Ulcer \\
\hline \multirow[t]{6}{*}{$\alpha 1$ (I) procollagen } & 3 & & $+(+)$ & + & +++ & - & ++ & - & ++ \\
\hline & 5 & - & $+(+)$ & + & +++ & - & ++ & - & ++ \\
\hline & 7 & - & ++ & + & +++ & - & $++(+)$ & - & ++ \\
\hline & 12 & - & ++ & + & +++ & - & $++(+)$ & - & ++ \\
\hline & 15 & - & + & - & +++ & - & ++ & - & + \\
\hline & 30 & - & - & - & + & - & - & - & - \\
\hline \multirow[t]{6}{*}{$\alpha 1$ (III) procollagen } & 3 & - & + & + & ++ & - & + & - & + \\
\hline & 5 & - & + & + & ++ & - & + & - & + \\
\hline & 7 & - & + & + & ++ & - & + & - & + \\
\hline & 12 & - & + & + & ++ & - & + & - & + \\
\hline & 15 & - & $(+)$ & - & ++ & - & - & - & + \\
\hline & 30 & - & - & - & - & - & - & - & - \\
\hline \multirow[t]{6}{*}{$\alpha 1$ (IV) procollagen } & 3 & - & + & + & ++ & - & $+(+)$ & - & + \\
\hline & 5 & - & + & + & ++ & - & $+(+)$ & - & + \\
\hline & 7 & - & + & + & ++ & - & $+(+)$ & - & + \\
\hline & 12 & - & + & + & ++ & - & $+(+)$ & - & + \\
\hline & 15 & - & $(+)$ & - & ++ & - & $(+)$ & - & + \\
\hline & 30 & - & - & - & + & - & - & - & - \\
\hline
\end{tabular}

,,-+++ , and +++ refer to the relative abundance of silver grains over individual cells after hybridisation with $\alpha 1$ (I), $\alpha 1$ (II), and $\alpha 1$ (IV) probes after six, 20, and 15 days of autoradiographic exposure, respectively, on the ulcer and contralateral sides: - , background signal; (+), 2-5 times; +, 5-10 times; ++, 10-15 times; and +++, $>15$ times the background signal as defined by hybridisation with sense (control) probes.

IMMUNOHISTOCHEMISTRY

Immunostaining for procollagens type I, III, and IV was performed on frozen serial sections of the same material used for in situ hybridisation. All three collagen types investigated could be detected in the lamina propria between the mucosal glands as well as in the submucosal layer in both control and contralateral specimens, with no obvious differences between them.

In the ulcer specimens marked differences in the intensity and timing of the deposition of interstitial collagen types I and III were observed as shown in table 2 . While dense deposits of collagen type I were seen as early as day 3 after ulcer induction, both in the submu-
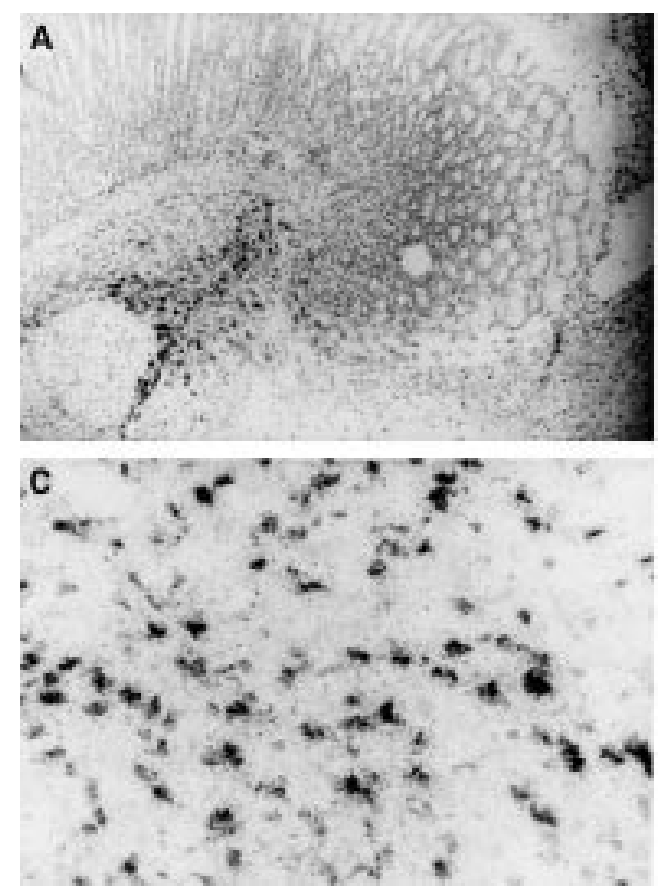

Figure 3: In situ hybridisation with the ${ }^{35}$ S labelled $\alpha 1(I)$ procollagen antisense RNA probe on rat gastric ulcer. There is strong cellular labelling predominantly in the submucosa $(A)$ as well as around the muscle bundles at the ulcer margin indicating a remarkable up regulation of collagen synthesis as early as day 3 after ulcer induction. (B) Magnification shows clustering of the autoradiographic signals in the submucosa. (C) A slightly weaker signal is observed at the ulcer base. (D) Parallel section hybridised with $a^{35} S$ labelled sense RNA probe for $\alpha 1$ (I) procollagen showing only a few background signals. Original magnification: $(A) \times 60 ;(B, C, D) \times 240$. cosa and the base of the ulcer margin (fig 6A), only delicate fibrous material reactive with procollagen type III specific antibodies was found around the glands of the lamina propria. On day 7, substantial deposition of type III collagen occurred at the ulcer base (fig 6B). The pattern of distribution of the collagens remained unchanged with the progress of ulcer healing in the mucosa and submucosa, with denser fibre deposition of collagen type I relative to type III and IV at all time points.

On day 3 after ulcer induction, procollagen type IV specific antibodies stained the basement membrane of normal and disrupted gastric glands, of blood vessels, and of smooth muscle cells of the intact muscularis mucosae
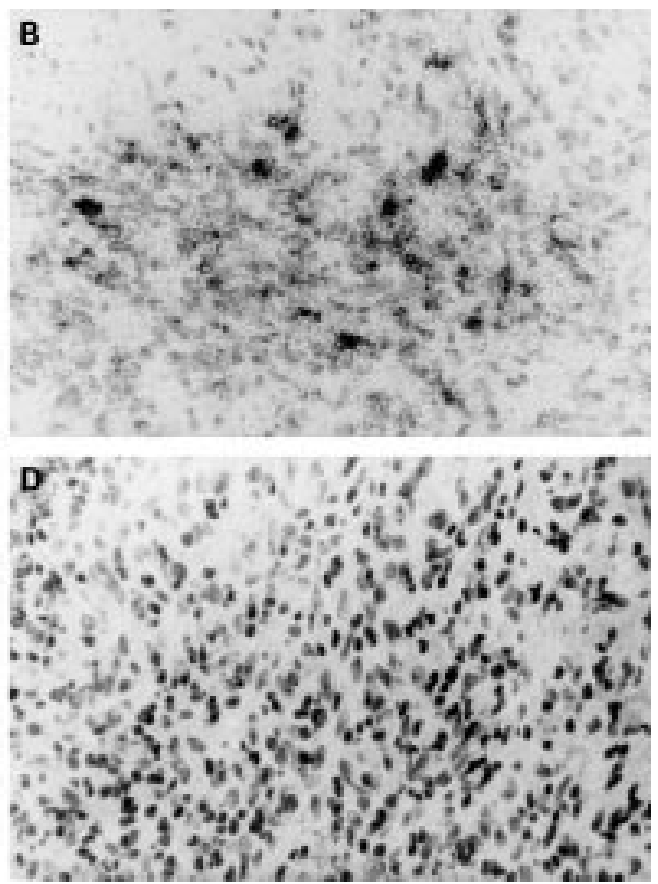


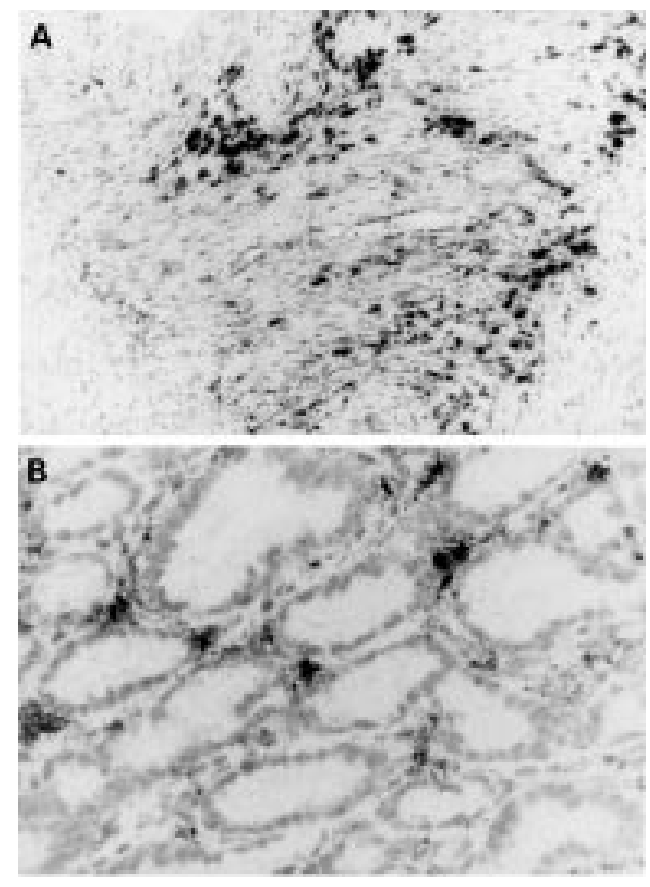

Figure 4: In situ hybridisation with the ${ }^{35}$ S labelled a1(I) procollagen antisense RNA probe on a rat gastric ulcer (12 days after induction). There is ubiquitous distribution of cells expressing RNA in cellular sheets along the muscle fibres of the muscularis propria $(A)$ or within the interglandular stroma of the lamina propria (B). Original magnification: $(A) \times 100 ;(B) \times 280$.

TABLE 2 Summary of immunohistochemical results

\begin{tabular}{clll}
\hline Antibody & $\begin{array}{l}\text { Days after } \\
\text { ulcer induction }\end{array}$ & $\begin{array}{l}\text { Mucosa } \\
\text { (ulcer margin) }\end{array}$ & $\begin{array}{l}\text { Submusoca } \\
\text { (ulcer base) }\end{array}$ \\
\hline$\alpha$ 1 (I) & 3 & + & +++ \\
procollagen & 5 & ++ & +++ \\
& 7 & ++ & +++ \\
& 12 & ++ & +++ \\
& 15 & ++ & +++ \\
$\alpha 1$ (III) & 30 & ++ & +++ \\
procollagen & 3 & - & + \\
& 5 & - & + \\
& 7 & + & ++ \\
& 12 & + & ++ \\
$\alpha 1$ (IV) & 15 & + & ++ \\
procollagen & 30 & + & ++ \\
& 5 & + & + \\
& 7 & + & + \\
& 12 & $+(+)$ & ++ \\
& 15 & $+(+)$ & ++ \\
& 30 & $+(+)$ & ++ \\
& & $+(+)$ & ++
\end{tabular}

,,-+++ , and +++ indicate the relative intensity of APAAP staining with individual primary antibodies during the healing process in ulcerated tissue compared with controls.

adjacent to the ulcer rim (fig 7A). With the progress of ulcer healing basement membrane staining of regenerating glands became denser, and patchy procollagen type IV deposition was also observed in the stromal fibrous tissue of the submucosa (fig 7B). Only faint immunostaining for collagen types I, III, and IV could be detected in the muscularis mucosae or propria (fig 8). In technically negative controls no immunostaining could be detected (fig 9).

Using digital photo analysis, the fractional area of procollagen staining in the submucosa was seen to be distinctly larger in all ulcer sections when compared with normal tissue. It
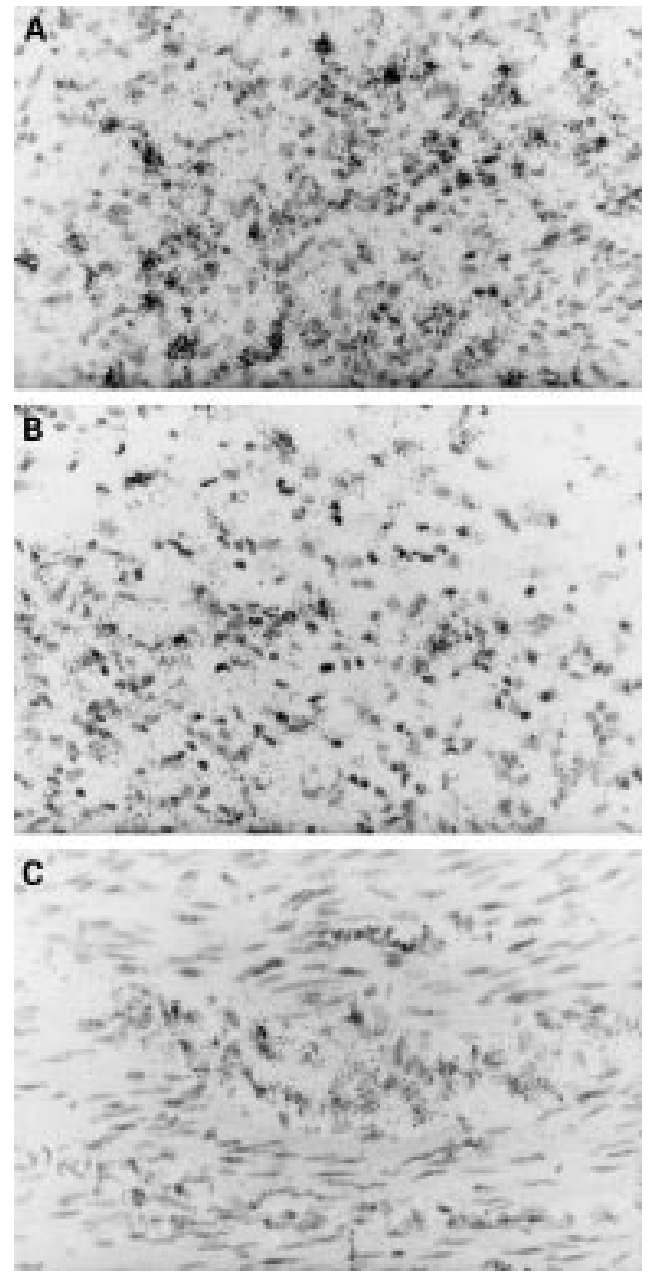

Figure 5: In situ hybridisation with the ${ }^{35} S$ labelled a1 (III) $(A)$ and $11(I V)$ procollagen $(B, C)$ antisense $R N A$ probes on a rat gastric ulcer three days after induction. (A) Compared with a 1(I) procollagen the density of the silver grains in the submucosal cells is slightly weaker. a1 (IV) procollagen gene transcripts are enhanced within mesenchymal cells of the submucosa $(B)$, and in the endomysial vascular connective tissue (C). Original magnification: $\times 280$.

was highest on the twelfth day after ulcer induction, with a slight but statistically insignificant decrease subsequently.

\section{Discussion}

Although therapeutic studies of gastric ulcer healing rely on endoscopy which is entirely based on visual and superficial observation to assess the healing process, ${ }^{21-23}$ both histological and molecular assessments of subepithelial mucosal restoration remain crucial for the determination of the degree and quality of ulcer repair.

We therefore studied the temporospatial pattern of procollagen RNA expression by applying in situ hybridisation to sections of acetic acid induced gastric ulcers in the rat. As early as the third day after ulcer induction, de novo expression of procollagen $\alpha 1$ (1) and $\alpha 1$ (III) RNA by the local proliferating fibroblasts and mesenchymal cells could be observed. The site with highest transcriptional activity was confined to the intact submucosa surrounding the ulcer margin which supports our previous 
findings on applying in situ hybridisation to human gastric ulcers. ${ }^{78}$ The density of spindle shaped cells that expressed procollagen RNA and which originated from the ulcer base below the zone of necrosis, was lower than that along the ulcer edges, indicating that tissue reconstruction initiates primarily at the ulcer rim, followed by further restitution from the ulcer base. In addition, strongly labelled cells were also found in the morphologically intact deeper layers - that is, in the endomysial connective tissue septa that ensheath the thick circular muscular layer of the muscularis propria as well as the longitudinal muscle. These cells are oriented towards the base of the ulcer, which showed a lower expression of procollagen $\alpha 1$ (I) and $\alpha 1$ (III) RNA at this stage. We thus hypothesise that the loose connective tissue of the deeper muscularis propria may serve as a reservoir for resting (myo-)fibroblasts, which on stimulation may differentiate, proliferate, and migrate towards the ulcer base to synthesise extracellular matrix and participate in mucosal repair. Similar findings for the intestine in Crohn's disease were obtained by Matthes $e t a l^{16}$ who showed that the highest levels of procollagen gene transcripts were in the muscularis propria and the muscularis mucosae. Cells expressing procollagen types I and III RNA showed identical distribution patterns in the various laminae including the lamina propria in which de novo collagen synthesis was less prominent than in other layers. For further characterisation of these cells a double labelling technique that comprises autoradiographic visualisation of mRNA probes preceded by immunohistochemical detection of $\alpha$-smooth muscle actin ${ }^{24}$ was applied in a sepa-

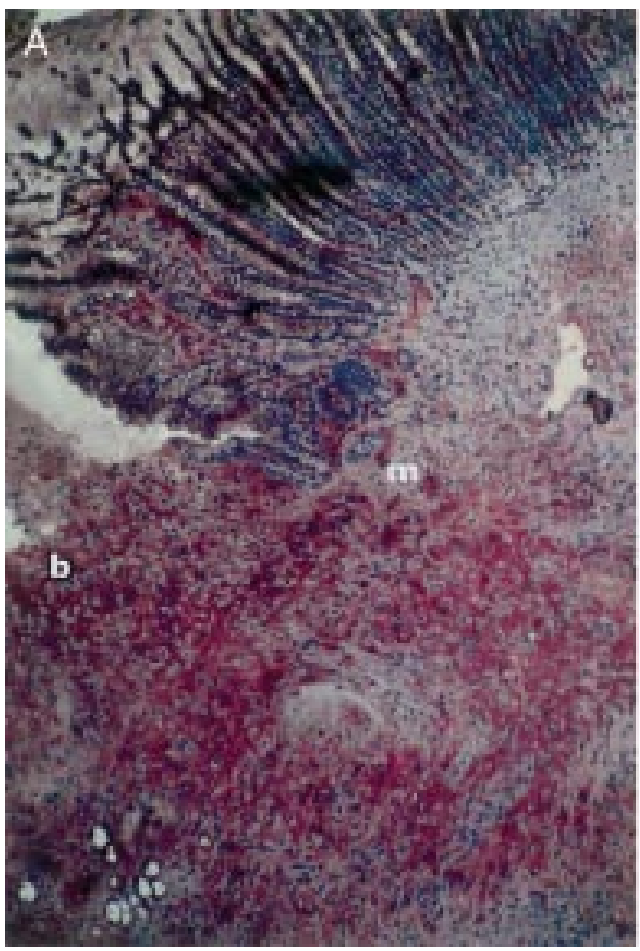

rate study (manuscript in preparation). A proportion of procollagen expressing cells in the submucosa and in the lamina propria, particularly in the subepithelial layer, stained strongly positive for $\alpha$-smooth muscle actin indicating that the de novo procollagen synthesis is, in part, a function of fibroblasts and probably myofibroblasts; this is in accord with previous findings. ${ }^{152526}$

The sites of procollagen $\alpha 1$ (IV) gene expression in the submucosa, in the loose granulation tissue infiltrating the muscularis propria, as well as in the serosal layer surrounding the ulcer, coincide with the occurrence of numerous fibroblast-like and endothelial cells that are a major source of type IV collagen, ${ }^{14}{ }^{15}$ a molecule that is the major constituent of all basement membranes and which is necessary for neoangiogenesis. This finding is in accord with studies that showed prominent deposition of collagen type IV and laminin at the ulcer edge. ${ }^{27}$ The strong hybridisation signals in the serosal cells for all procollagen RNAs investigated are obviously related to the severe tissue injury produced by the local application of acetic acid. The enhanced expression of procollagen gene transcripts in the enlarged submucosa of gastric specimens contralateral to the ulcer site appears to reflect spread of inflammation beyond the macroscopically injured zone.

Down regulation of procollagen RNA expression occurred in our tissue specimens on day 30, late in the process of mucosal restoration. This may be due to a feedback mechanism resulting from the increasing contact of the initially activated cells with the now

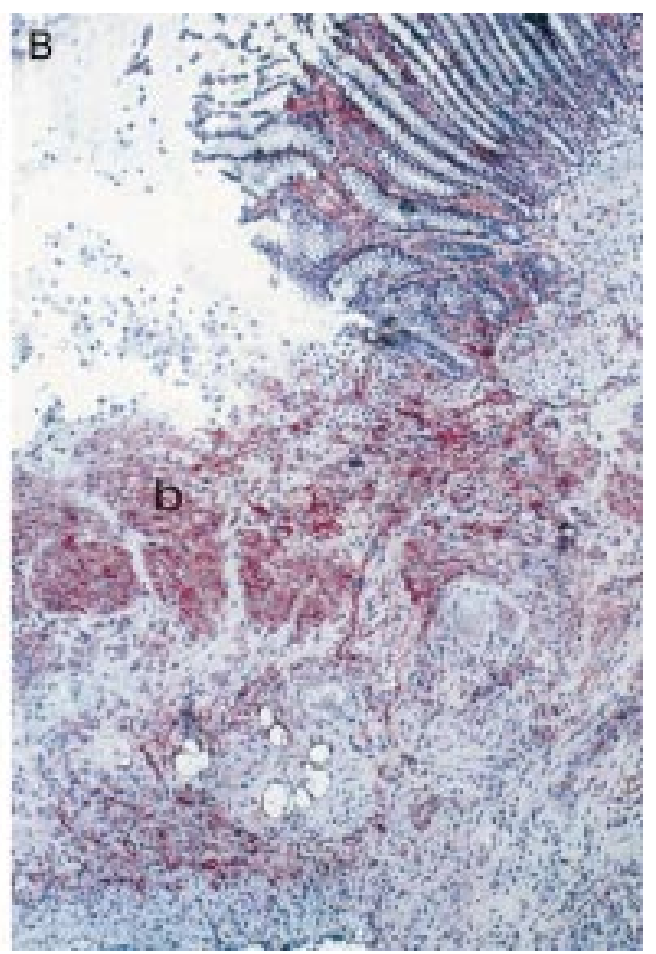

Figure 6: Immunostaining for collagens type I and III (APAAP technique). (A) Intense collagen specific staining (red colour) is already observed on day 3 after ulcer induction both in the submucosa and the base (b) of the ulcer margin ( $m$ ). (B) On day 7 substantial deposits of collagen type III are detected in the lamina propria and at the ulcer base (b). Original magnification: $\times 60$ 

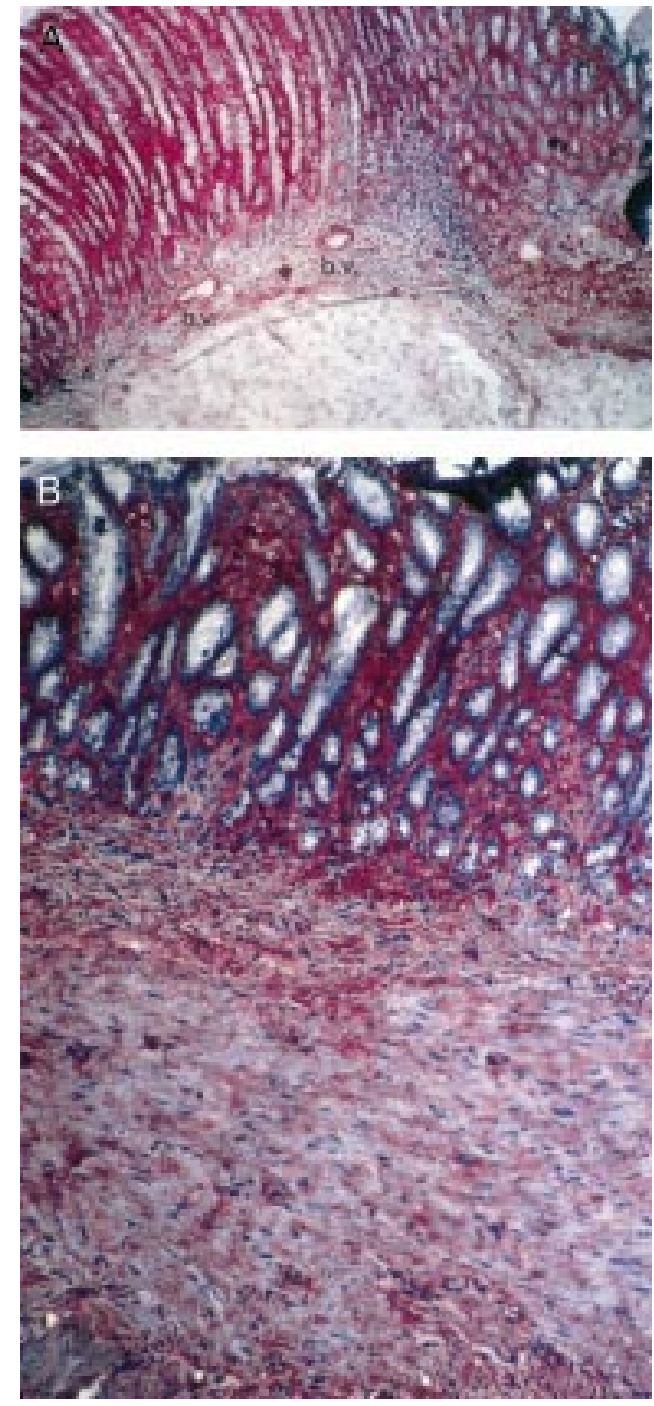

Figure 7: Immunostaining for type IV procollagen (APAAP technique). (A) On day 3 after ulcer induction there is deposition around blood vessels (b.v.) and in the basement membranes of the gastric glands and around the inflammatory cellular infiltrate at the ulcer rim. (B) With progression of ulcer healing dense procollagen IV deposition is observed in the stromal tissue of the lamina propria and of the submucosa. Original magnification: $\times 60$.

restored connective tissue matrix, ${ }^{28}{ }^{29}$ thus preventing excessive scarring.

In parallel to the strong expression of procollagen $\alpha 1(\mathrm{I}) \mathrm{RNA}$, collagen specific immunostaining showed intense deposits of the corresponding collagen type already on day 3, particularly in the lamina propria and submucosa at the ulcer margin. In contrast, the enhanced procollagen $\alpha 1$ (III) and $\alpha 1$ (IV) RNA expression on day 3 was not paralleled by corresponding protein deposition in the ulcer tissue at this early phase of healing, indicating different post-transcriptional regulation or increased polypeptide turnover of the respective collagens. However, the sites of procollagen RNA expression corresponded with the deposition of the respective proteins except for the muscularis mucosae and the muscularis propria, where collagen immunoreactivity remained weak. We conclude that cells primarily contributing to collagen synthesis may be

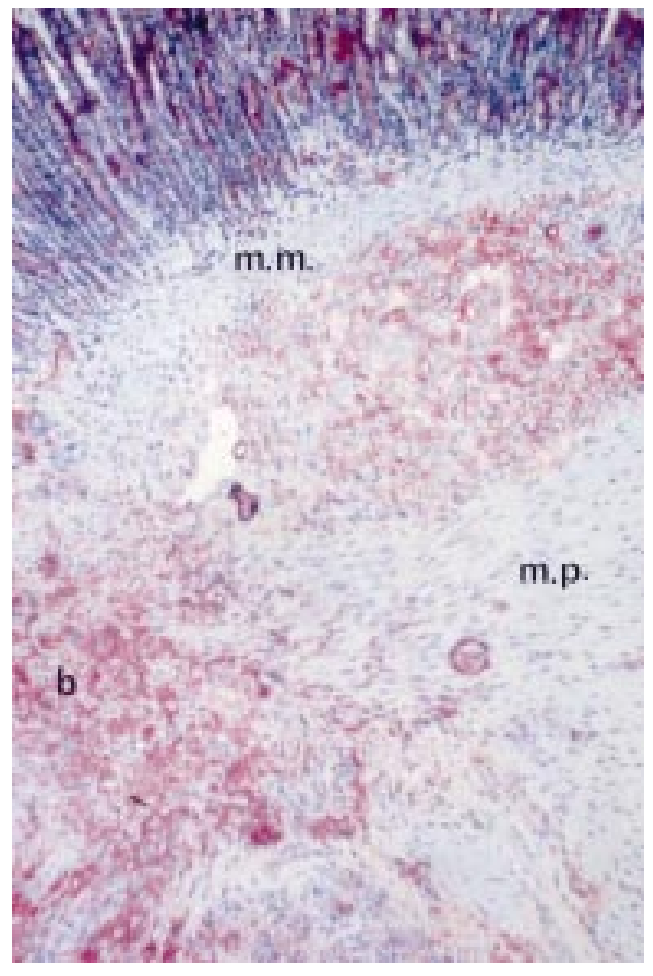

Figure 8: Immunostaining for type I collagen (APAAP technique) on day 7 after ulcer induction. Only faint collagen type I deposition is found in the muscularis mucosae (m.m.) or propria (m.p.); (b) indicates ulcer base. Original magnification: $\times 60$.

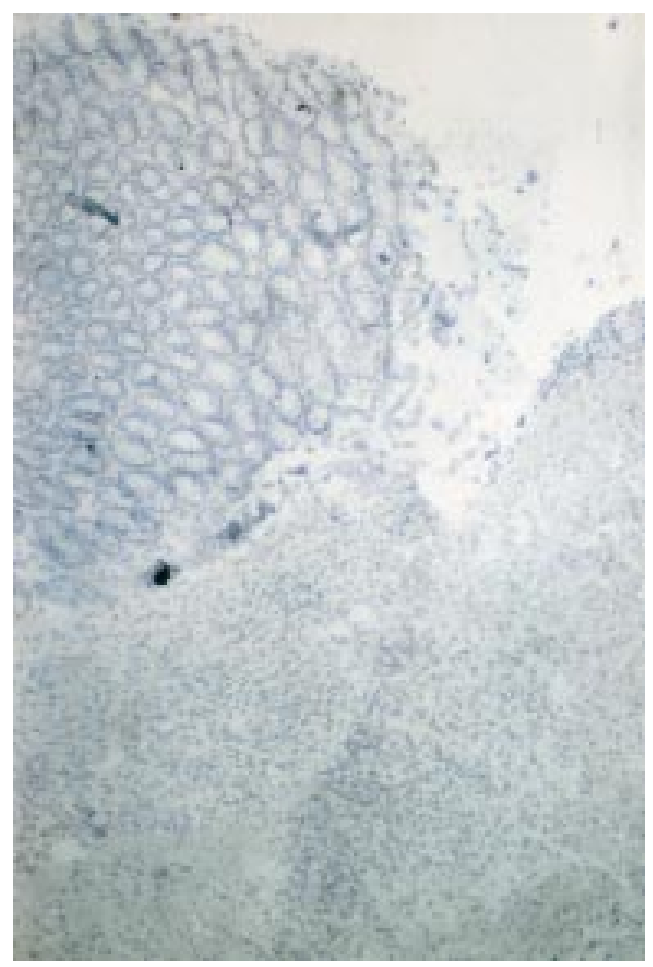

Figure 9: Immunostaining (APAAP technique) with non-immune serum in a three day old negative control ulcer specimen. Original magnification: $\times 60$.

recruited and migrate from these layers to the area of the ulcer.

The overall deposition of procollagens, as demonstrated by digital photo analysis, seems to peak between the twelfth and the fifteenth 
day, after which a slight reduction occurs, probably reflecting remodelling necessary to avoid excessive scarring. Accordingly, these changes coincide with the onset of scar formation observed macroscopically on the twelfth day, after which the ulcer margin becomes undefined due to scar resorption.

In summary, our data show that de novo collagen synthesis of the gastric mucosa is stimulated maximally in the ulcerated area whereas it was found at only minimal levels in controls. Semiquantitative assessments by both in situ hybridisation and immunohistochemistry revealed that collagen type I is the most abundant collagen in the gastric stroma. This reflects the importance of collagen type I as a major component of thick collagen fibrils for providing support and structural stability to the disrupted mucosa. The intensity of the autoradiographic signals of $\alpha 1$ (III) and $\alpha 1$ (IV) procollagens associated with neovascularisation were slightly weaker than those for type I, in line with the weaker immunostaining of the respective proteins, which revealed a rather delicate and loose reticular network. In addition, collagen synthesis is not only triggered in the submucosa as previously described, but also in deeper layers, such as the muscularis propria and serosa, indicating the coordinated interaction of all structural layers of the gastric wall during the process of gastric ulcer healing.

Further studies should focus on the mechanisms that regulate collagen degradation, and the exact nature and dynamics of other cells involved in RNA expression including during the first few hours after ulcer induction.

The authors thank Drs D Rowe, Farmington; D J Prockop, Philadelphia; and G Vogeli, Kalamazoo, for the kind gift of the DNA probes, as well as Mrs G Puls and Mrs U Tank for their excellent technical assistance. The financial support of the Deutsche Forschungsgemeinschaft (Grant He 1330/2-1) is acknowledged.

1 Reubi JC, Waser B, Schmassmann A, Halter F. Persistent lack of somatostatin receptors of gastric mucosa in healing ulcers in rat. Gastroenterology 1994; 107: 339-46.

2 Mikami H, Watanabe S, Hirose M, Sato N. Role of extracellular matrix in wound repair by cultured gastric mucosal lular matrix in wound repair by cultured gastric mucosa

3 Tarnawski A. Cellular mechanisms of gastric ulcer healing. In: Domschke W, Konturek SJ, eds. The stomach. Physiology, In: Domschke W, Konturek SJ, eds. The stomach. Physiology, pathophysiology and treat

4 Schuppan D, Herbst H, Milani S. Matrix, matrix synthesis, and molecular networks in hepatic fibrosis. In: Zern MA Reid LM, eds. Extracellular matrix. Chemistry, biology, and pathobiology with emphasis on the liver. New York: Marcel Dekker, 1993: 201-54.

5 Gillessen A, Voss B, Rauterberg J, Domschke W. Distribution of collagen types I, III, and IV in peptic ulcer and normal gastric mucosa in man. Scand $\mathcal{F}$ Gastroenterol 1993; 28 688-9.

6 Lu SY, Tarnawski A, Stachura J, Thillai I. Sequential expression and distribution of fibronectin, laminin and collagens III and IV during experimental gastric ulcer healing lagens III and IV during experimental gastric

7 Gillessen A, Shahin M, Pohle T, Foerster E, Domschke W.

Collagen mRNA and fibronectin are increased in healing gastric ulcers in man. F Physiol Pharmacol 1995; 46: 57-62.
8 Gillessen A, Shahin M, Pohle T, Foerster E, Krieg TH, Domschke W. Evidence of de novo collagen synthesis in
healing human gastric ulcers. Scand 7 Gastroenterol 1995; 30: $515-8$.

9 Okabe S, Roth JLA, Pfeiffer CJ. A method for experimental, penetrating gastric and duodenal ulcers in rats. Am $\mathcal{F} \mathrm{Dig}$ Dis 1971; 16: 277-84.

10 Tarnawski A, Holander D, Stachura J, Krause WJ, Eltorai M, Dabros W, et al. Vascular and microvascular changes key factors in the development of acetic acid-induced gastric ulcers in rats. $\mathcal{F}$ Clin Gastroenterol 1990; 12 (suppl 1): 148-57.

11 Genovese C, Rove D, Kream B. Construction of DNA sequences complementary to rat $\alpha 1$ and $\alpha 2(\mathrm{I})$ collagen mRNA and their use in studying the regulation of type I collagen synthesis by 1,25-dihydroxyvitamin D. Biochemistry 1984; 23: 6210-6.

12 Liau G, Yamada Y, de Crombrugghe B. Coordinate regulation of the levels of type III and type I collagen mRNA in tion of the levels of type III and type I collagen mRNA in
most but not all mouse fibroblasts. $\mathcal{F}$ Biol Chem 1985; 260: 531-6.

13 Nath P, Laurent M, Horn E, Sobel ME, Zon G, Vogeli G. Isolation of an $\alpha 1$ type-IV collagen cDNA clone using a synthetic oligodeoxynucleotide. Gene 1986; 43: 301-4.

14 Milani S, Herbst H, Schuppan D, Kim KJ, Riecken EO, Stein H. Procollagen expression by nonparenchymal cells in experimental biliary fibrosis. Gastroenterology 1990; 98: 175-84.

15 Milani S, Herbst H, Schuppan D, Hahn EG, Stein H. In situ hybridization for procollagen types I, III and IV mRNA in normal and fibrotic rat liver: evidence for predominant expression in nonparenchymal liver cells. Hepatology 1989; 10: $84-92$.

16 Matthes H, Herbst H, Schuppan D, Stallmach A, Milani S, Stein $\mathrm{H}$, et al. Cellular localization of procollagen gene transcripts in inflammatory bowel diseases. Gastroenterology 1992; 102: 431-42.

17 Cordell JL, Falini B, Erber WN, Ghosch AK, Abdulaziz Z, Mac-Donald S, et al. Immunenzymatic labeling of monoclonal antibodies using immune complexes of alkaline phosphatase and monoclonal antialkaline phosphatase 200 .

18 Becker J, Schuppan D, Benzian H, Bals T, Hahn EG, Cantaluppi $\mathrm{C}$, et al. Immunohistochemical distribution of collagen types IV, V, VI and procollagen types I and III in human bone and dentine. $\mathcal{F}$ Histochem Cytochem 1987; 34: 1417-29.

19 Schuppan D, Cantaluppi MC, Becker J, Veit A, Bunte T, Troyer D, et al. Undulin, an extracellular matrix glycoprotein associated with collagen fibrils. $\mathcal{F}$ Biol Chem 1990; 265: 8823-32.

20 Völker W, Böhm A, Schmidt A, Svahn CM, Gellerbring A-K, Mattssoon C, et al. Inhibition of smooth muscle cell proliferation and neointimal growth by low-anticoagulant proliferation and neointimal growth by low-anticoagulant 546-50.

21 Takemoto T, Namiki M, Ishikawa M. Ranitidine and sucralfate as maintenance therapy for gastric ulcer disease: endoscopic control and assessment of scarring. Gut 1989; 30: 1692-7.

22 Maruoka A, Fujishima H, Misawa T, Chijiiwa Y, Nawata H. Evaluation of acetic acid-induced gastric ulcers in dogs by endoscopic ultrasonography. Scand f Gastroenterol 1993; 28: $1055-61$.

23 Tarnawski A, Douglass TG, Stachura J, Krause WJ. Quality of gastric ulcer healing: histological and ultrastructural assessment. Aliment Pharmacol Ther 1991; 5: 79-90.

24 Herbst H, Frey A, Heinrichs O, Milani S, Beckstein OW, Neuhaus $\mathrm{P}$, et al. Heterogeneity of procollagen types I and IV expressing liver cells in vivo. Histochem Cell Biol, in press.

25 Martens MFW, Huyben CMLC, Hendriks Th. Collagen synthesis in fibroblasts from human colon: regulatory synthesis in fibroblasts from human colon: regulatory aspects and $1664-70$.

26 Ishizaki M, Zhu G, Haseba T, Shafer S, Kao, WW-Y. Expression of collagen I, smooth muscle $\alpha$-actin, and vimentin during the healing of alkali-burned and lacerated corneas. Invest Ophthalmol Vis Sci 1993; 34: 3320-8.

27 Ernst H, Grunert S, Schneider HT, Beck WS, Brune K, Hahn EG. Distribution of extracellular matrix proteins in indomethacin-induced lesions in the rat stomach. Scand $\mathcal{F}$ Gastroenterol 1995; 30: 847-53.

28 Mauch C, Hatamochi A, Scharffetter K, Krieg T. Regulation of collagen synthesis in fibroblasts within a threedimensional collagen gel. Exp Cell Res 1988; 178: 493-503.

29 Nüsgens B, Marill C, Lapiere C, Bell E. Collagen biosynthesis by cells in a tissue equivalent matrix in vitro. Collagen Related Research 1984; 4: 351-7. 